\title{
Blood Bank Connect Android Application
}

\author{
${ }^{1}$ Isha Talathi, ${ }^{2}$ Nishikumar Patel, ${ }^{3}$ Dhruvin Kamdar, ${ }^{4}$ Ankush Hutke \\ ${ }^{1,2,3}$ Student, ${ }^{4}$ Assistant Professor, MCT's Rajiv Gandhi Institute of Technology, Mumbai, India, \\ 1ishatalathi_22@yahoo.in, ${ }^{2}$ nishittpatel@gmail.com, ${ }^{3}$ dhruvinkamdar@gmail.com, \\ 4ankush.hutke@mctrgit.ac.in
}

Abstract: In today's globalized world the surge of smartphones and social networking sites across the world has increased rapidly, which has also become one of the most efficient ways to solve problems. Blood is an important constituent of the human body also known as the RIVER OF LIFE. Blood banks oftentimes suffer from a shortage of blood; therefore, advertisements are frequently seen on social networks urging healthy individuals to donate blood. With a growing population and advances in medical treatments and procedures requiring blood transfusions, the demand for blood continues to increase. To resolve this, communication between the hospital, blood bank, donor, and the receptor is important. Emergencies, like accidents, create an immediate, critical need for specific blood types. Despite increasing requirements for blood, only about $7 \%$ of the Indian population donates blood. Hence, we developed a new idea, just a touch away. Donors will be prompted to enter individual details, like name, phone number, and blood type thus facilitating the search process. One can quickly check for contacts matching related blood groups and reach out to them via Phone call/SMS through the Blood Bank application. This application is based on location (GPS), operational on an android platform, has a vision towards making the most important fluid running in our body available to everyone.

Keywords — Android, Blood Transfusions, GPS, emergency situations, matching blood groups, Receptor.

\section{INTRODUCTION}

Human Blood is an important fluid that transports the oxygen, nutrients and waste products outside and within the cells of the human body. Hence for blood to be in more excessive for usage at any time for those that require, also in case of emergencies it results in blood donation which has to be gathered, preserved and stored for later use, this is called blood bank for transfusion. The process of receiving blood into person circulation intravenously through the vein is called as blood Transfusion.

Blood Bank integration System is to create an e-Information about the donor and organization that are related to donating the blood. Blood bank System is an android based system that is designed to store, process, retrieve and analyze information concerned with the administrative and inventory management within a blood bank. The task of blood bank is to receive blood from various donors, to monitor the blood groups in the database and to send the required blood during need to the hospital in case of emergencies. This system is developed for an android phone where blood banks can look for donors in their nearby area who will be available in a quick time. Using this application, one who is interested in donating the blood can register himself/herself. Similarly, if any organization wants to register itself with this site that can also register. The additional feature of this application is, if any general consumer wants to request blood online he can also take the help of this system. Blood donors can also look for blood banks and blood donation camps in an area nearest to them to donate blood. The user can easily register by entering some personal details such as name, organization name, address, e-mail and phone number. An account for the user will be created and he/she can log in to get the required information. Admin is the main authority who can do addition, deletion, and modification when required. Notifying the donor about the need for the blood is the most important task of the system.

This system consists of an application that is present on the donor's android-phone, a website that acts as an interface for the users of the system and it also uses a database for storing the donor's data. So this project aims that in a very short span it provides users with many facilities. It provides sophisticated management of blood, a list of hospitals, blood banks and donors online. The main purpose of this system is to interconnect all the blood banks, hospitals,

donors into a single network, validate, store various data and information on blood and health of each individual. This system stores data over a centralized server in the form of a database where the individuals' information cannot be accessed by a third party. 


\section{LITERATURE SURVEY}

A lot of research work has been done in the past that are related to connecting blood donor and receiver better. They all use different platforms to execute their idea.

[1] This application updates all the information on time about the donors where the administration gets all information of blood bank management system. Donor will get a prompt to enter an individual's details, like phone number, name and blood group. When the blood is required urgently, you can check for blood banks or hospitals matching a particular blood group and reach out to them via the application.

[2] The system makes sure that the blood is available to the patient when that person needs it. There will be an android app and a web portal to make this communication faster. The aim is to create an e-Information about the donor and organization that are involved in the blood donation. The Methodology used in the making of this system uses GPS. The Proposed system will be used in Hospitals, Blood banks, for Donors and Receivers whoever registers to the system.

[3] The information that the blood banks can retrieve from their database is: number of patients that suffer a particular disease for each age group; number of accidents expected in a holiday season for age group and blood type; and amount of blood donation expected by age group and blood type. This information is then used to calculate the amount of a certain blood type that is needed and the amount of blood that will be available during the exact time period of that year. If the bank notices that they are running out of inventory, it can take different initiatives to increase this level such as initiating special drives to collect blood or borrowing from other blood banks.

[4] This paper aims to develop a blood donation service to help in managing blood donor records and control the blood distribution in different parts of the country based on the demands. In Bangladesh, the blood donation service offers functionality to quickly access the records of the donors collected from different parts of the country. It enables monitoring of the performance and results of the activity of blood donation.

[5] This paper aims to reduce the stress that sometimes comes with the different means of communication. The most used mean of communication has been proved to be email. However, email communication has a major disadvantage that to access the mailbox, it requires a working and an active connection to the internet which is usually not cheap and average individual cannot easily afford it. This work was developed so that when you use email as a mean of communication, you don't face such problems by helping the e-mail account holder to forward his email that he just got by SMS to the user's cell phone with or without access to the internet on the user's handset.

\section{Proposed System}

The proposed system is a combination of a web application and an android application. The user is provided with an efficient and convenient platform to request or donate blood.

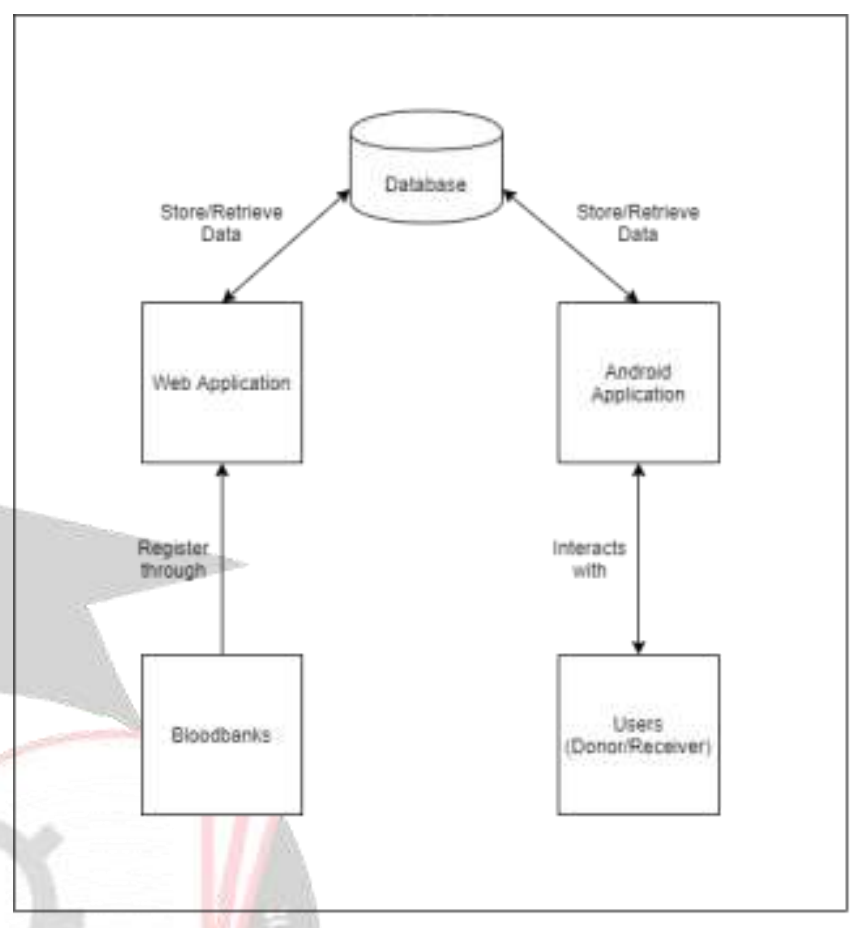

Figure 1: Architecture of Proposed System

It consists of two modules:

1. Web Application (For Blood Banks)

2. Android Application (For Users)

Blood Banks can register themselves on the system by using the web application's registration form. This form includes all the details about the blood bank including its location which can later be used to provide directions.

The android application is equipped with two options namely donor and receiver. The user who is willing to donate blood signs up using the donor option. After login, the application displays the list of upcoming blood donation drives in his vicinity. He also has the option of making himself available for any emergency blood requirements.

The receiver option is to be used by the user who needs blood. He is required to signup using the receiver option and after signing up he can make a request. According to the request made, he is displayed with all the available blood banks in his vicinity. He is also provided with a list of volunteering people matching the blood requirement. The user can then select people or blood banks from this list and send them a notification. He is also provided with contact details of available donors for reaching out manually. 


\section{RESUlt AND DiscuSsion}

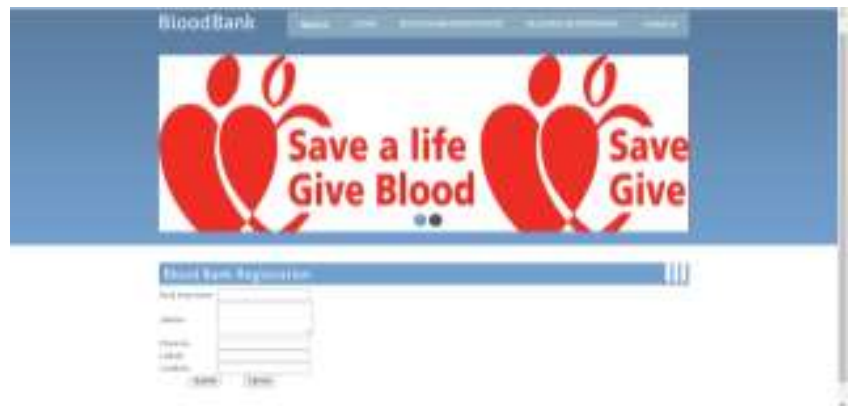

Figure 2: Registration Form

There are many Web Based Application which stores and provides information about both users like donor of blood and blood bag applicant. Blood Bank Connect Application is a system that forms an intermediate between the donor and the blood banks, receptor directly in the time of any kind of emergency/urgency in a very convenient way.

The figure above is a screenshot of the web page which is controlled by the admin. All the data of registered donors, blood banks are stored here. The blood banks need to register using this web application providing information regarding the name, location (using latitude and longitude), address and contact number. Only the admin can update, add or delete the database information no third party can access this page.

The android Based application is user friendly making it easier for the needy.
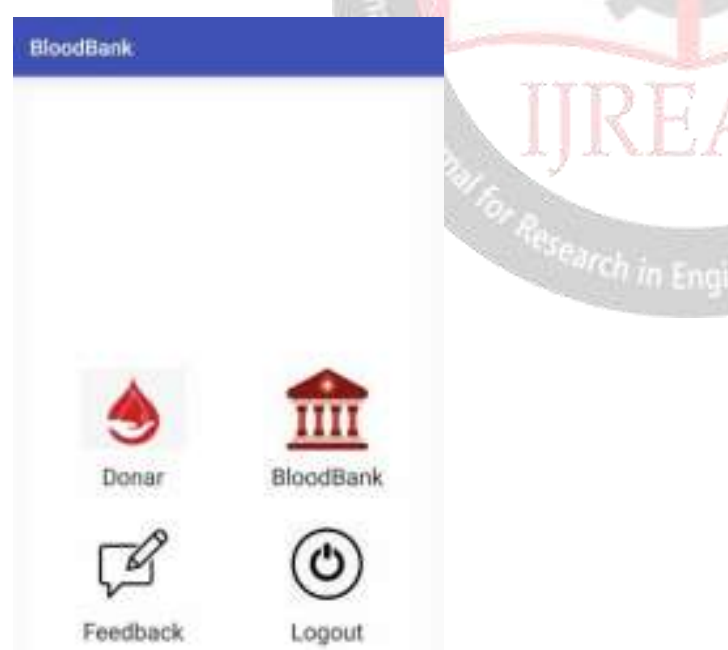

\section{Figure 3: Android Application}

This is the page that will first pop-up when the receiver/donor opens the android based application. Donors and receivers need to create an account and add some personal details like name, e-mail id and contact information. The receiver can find donors and blood banks after clicking on the respected icons. It will display blood banks/donors available within $5 \mathrm{Km}$ radius of the receiver. Below are the screenshots of the android application indicating examples of blood banks and donors within $5 \mathrm{Km}$ of the registered receiver.

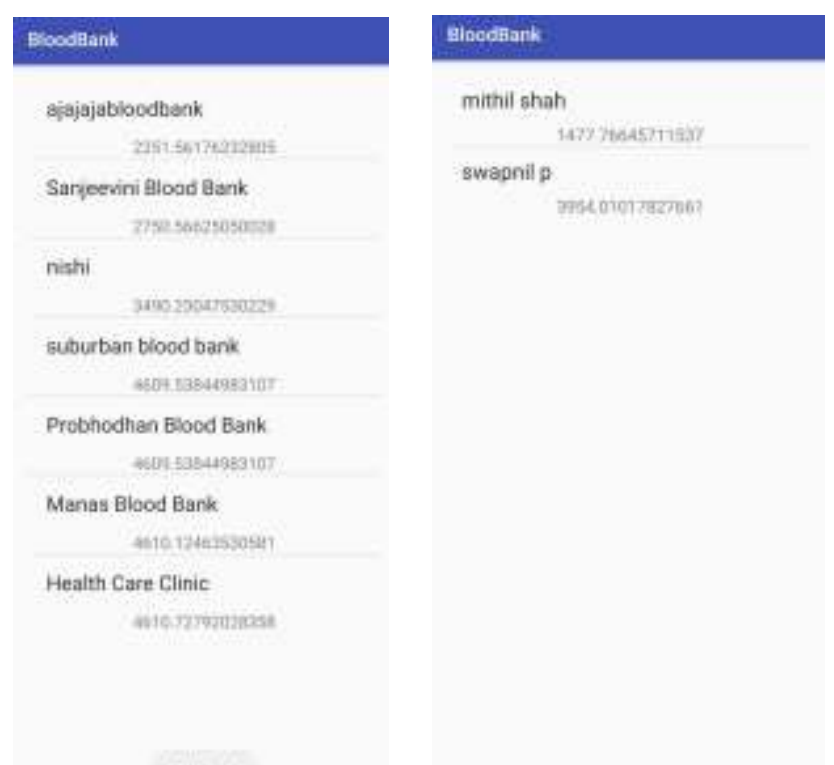

Figure 4: Blood Banks

Figure 5: Individual Donors

\section{Conclusion}

Based on the results, this study concluded that online management of the blood bank donation system is much better than the manual system which leads to an easy and effective way. The sole purpose of this project is to develop an electronic system that will link all donors, hospitals, blood banks and receptors. The proposed system interconnects communication between blood donors and blood donation centers so that the appropriate donor can be reached just on time. This system will help in a crisis in which there is an urgency of blood. Furthermore, people will be able to see the nearby hospitals and the list of patients located nearby using mobile GPS in need of blood supplies via the application. They will be able to register as donors and thus receive a notification from their local clients who need blood or to donate blood in cases of need. The application will help develop public awareness amongst its visitors to the hospitals' need for blood to supply the appropriate donors. In future the work will be focused on enhancing these models more to allow integration with blood donor management systems including inventive ways of visualization.

\section{ACKNOWLEDGMENT}

We would like to express our gratitude to MCT's Rajiv Gandhi Institute of Technology for aspiring guidance, invaluably constructive criticism and friendly advice and opportunities. We are sincerely grateful to Prof. Ankush Hutke for their support and guidance. 


\section{REFERENCES}

[1] Android Blood Bank, Vol. 4, Issue 11, November 2015.

[2] Implementation of Blood Donation Application using Android Smartphone, vol.2 Issue1 February 2013.

[3] Automated online Blood Bank Database, 2012 Annual IEEE.

[4] mHealth; Blood donation Service, 2013 International Conference 2013 IEEE:

[5] Push Notify: Push Server Application, vol.2 Issue1 February 2013.

[6] Towards "digital blood-banking", ITU-T Kaleidoscope: Innovations for Digital Inclusions Spyropoulos, B., Botsivaly, M, Tzavaras, A., Spyropoulos, P., 2009. K-ID I2009.

[7] Javed Akhtar Khan and M. R Alony "A New Concept of Blood Bank Management System using Cloud Computing for Rural Area (INDIA)", International Journal of Electrical, Electronics and Computer Engineering 4(1): 20-26(2015).

[8] Rohini Patil, Puja Pawar, Madhu Poi, Tejashri Patil, Prof. Namrata Ghuse "Blood Donor's safety using Data Mining”, 978-1- 4673-7910-6/15/31.00c 2015 $\operatorname{IEEE}(2015)$.

[9] AN ANDROID APPLICATION FOR VOLUNTEER BLOOD DONORS by Sultan Turhan. [4] Arif. M. Sreevas. S. Nafseer. K. and Rahul. R. (2012), 'Automated online Blood bank database', India Conference (INDICON), Annual IEEE.

[10]H. Chen and X. Jia. "New requirements and trends of mHealth." In IEEE $141 \mathrm{~h}$ International Conference on eHealth Networking, Applications and Services (Healthcom), pp. 27-31, 2012. 